Roberto Cavalcanti de Albuquerque, professor titular de economia na Universidade Federal de Pernambuco, exercendo atualmente o cargo de Secretário-Geral adjunto do Ministério do Interior.
Roberto Cavalcantide Albuquerque

$E N-00003283-1$

\title{
Habitação e desenvolvimento urbano no Brasil
}

1. Pesquisa Nacional por Amostra de Domicilios, IBGE, 1976.

\section{A Dimensão do problema habitacional brasileiro}

Nos primeiros vinte anos, estima-se em 15 milhões a demanda por habitações a ser gerada, nas cidades, apenas pelo crescimento esperado da população urbana brasileira.

Na década passada, o crescimento absoluto da população urbana no Brasil superou, pela primeira vez em sua história, o da população total. A população urbana cresceu à taxa média geométrica de $4,5 \%$ ao ano, a população total, a $2,5 \%$ e a população rural decresceu, anualmente, a $0,6 \%$. A população urbana cresceu em $28,4 \mathrm{mi}$ Ihões; a total, em 25,9 milhões e a população rural reduziu-se em 2,5 milhões. Em todas as grandes regiões - inclusive no Nordeste - a população urbana superou a população rural, atingindo, no país como um todo, $68 \%$ da população total.

No ano 2000, um a população total do Brasil deverá atingir 177 milhões, admitindo-se, no período 1980-2000, crescimento médio geométrico anual de $2 \%$. A população urbana será de 145 milhões, na hipótese de crescimento de $3 \%$ ao ano e a rural, de 32 milhões decrescendo a $1 \%$, anualmente. A proporção da população urbana no total deverá, portanto, elevar-se para $82 \%$, participação já superada, em 1980, na região Sudeste. O crescimento absoluto da população urbana será, assim em duas décadas, de 65 milhões, gerando demanda por habitações de cerca de 15 milhões de unidades.

Ressalte-se que essa demanda por habitações no meio urbano não leva em conta o déficit habitacional existente em 1980, que pode ser estimado em 9 milhões de domicílios, considerados apenas os efetivamente ocupados.

A propósito, pesquisa de $1976^{1}$ indica que, naquele ano, 7,1 milhões de domicílios particulares permanentes urbanos no país apresentavam condições inadequadas de abastecimento de água e 
esgoto sanitário ou tipo de construção não-durável ou rústica, correspondendo a $48,7 \%$ do total de 14,5 milhões de domicílios existentes.

Como, entre 1976 e 1980, a população urbana do país cresceu em cerca de 13 milhões, gerando demanda por habitacões de cerca de 3 milhões, é pouco provável que o déficit encontrado em 1976 tenha se reduzido, sequer em termos relativos. Na verdade, estudo conduzido recentemente pelo Ministério do Interior, no âmbito do Conselho Nacional de Desenvolvimento Urbano - C.N.D.U., indica que a demanda gerada pelo crescimento demográfico urbano teria sido de três a quatro vezes superior à oferta de habitações, entre 1976 e 1980. E mesmo admitindo-se que a participação dos domicílios urbanos considerados inadequados no total dos domicílios tenha se mantido constante, entre 1976 e 1980, o déficit habitacional urbano, em 1980, situa-se na ordem de 9 milhões.

Pode-se, portanto, estimar que a demanda por habitações urbanas no Brasil, nos próximos vinte anos, deverá ser de cerca de 24 milhões, ou seja, o equivalente, em média, a 1.200.000 habitações por ano.

Não se considerou, até aqui, a questão da habitação no meio rural, não menos grave, ainda que de dimensão muito menor que a
urbana.

É certo que a população rural decresceu, em termos absolutos, entre 1970 e 1980, o que se reflete na proporção de domicílios fechados ou vagos, de $16 \%$, encontrada em 1980 (1,5 milhão de domicílios desocupados, para um total de 9,2 milhões de domicílios particulares rurais, segundo o censo demográfico de 1980). É certo, também, que se antecipa, para os próximos vinte anos, redução da população rural de 7 milhões de pessoas.

Mas é bom frisar que, em 1976, 48\% dos domicílios rurais eram tidos como rústicos, $86 \%$ abasteciam-se, de forma precária, de água, 95\% não tinham instalação sanitária de qualquer espécie ou dispunham apenas de fossas rudimentares e $81 \%$ não possuiam instalação elétrica.

De outra parte, a expansão da fronteira agrícola para novas áreas, incorporadas à economia nacional, deverá determinar demanda por habitações no meio rural que não guarda nenhuma relação com o decréscimo esperado para a população rural total.

Considerados esses fatores, não seria exagerado estimar a demanda por habitações rurais, nos próximos vinte anos, na ordem de 6 milhões, aí considerados tanto o déficit habitacional existente nas zonas rurais já ocupadas, quanto a demanda da ampliação da fronteira agrícola do país.

Pode-se, portanto, concluir que a demanda global por habitações no Brasil, nos próximos vinte anos, é da ordem de 30 milhões, sendo que 20\% (6 milhões) dessa demanda deverão gerar-se no meio rural e $80 \%$ (24 milhões), no urbano. No meio urbano, cerca de $63 \%$ (15 milhões) da demanda deverão decorrer do aumento popu- 
lacional e os restantes 27\% (9 milhões) serão determinados pelo déficit habitacional estimado para 1980.

\section{O Desejado e o possível}

Esses números dão a medida do esforço que a sociedade brasileira deverá fazer, nesta e na próxima década, para obter melhoria significativa nas condições habitacionais hoje prevalescentes: 1,5 milhão de habitações a serem construídas ou melhoradas, anualmente.

E viável essa tarefa? Como se compara com o que se foi capaz de empreender no campo da habitação, até agora? Quais as medidas que devem ser adotadas para realizá-la? O que se deve e se pode objetivamente fazer, no curto e médio prazos de forma consoante com os objetivos de mais longo prazo até aqui indicados?

Para tentar encaminhar respostas a essas indagações, creio ser fundamental colocá-las na perspectiva mais ampla da problemática do desenvolvimento nacional.

\section{O Desafio dos retardatários do desenvolvimento}

O grande desafio que enfrentam hoje países como o Brasil é o de promover, no decurso de poucas décadas, transformações econômicas, sociais e políticas que as nações hoje avançadas levaram séculos para realizar. Esses paises buscam atingir, concomitantemente, os objetivos, nem sempre facilmente conciliáveis no tempo, de eficiência econômica, bem-estar coletivo e liberdade política em contexto social em que ponderáveis contingentes da população ainda vivem situações que se aproximam mais das sociedades tradicionais do que das modernas economias de mercado.

O fato de que, até há três séculos, nenhum sistema social de alguma importância pôde produzir mais do que 400 dólares, per capita, anualmente, indica, com clareza, os limites impostos pelas sociedades tradicionais ao desenvolvimento das forças produtivas. Esse desempenho, pobre quando medido pelos padrões modernos de eficiência econômica, determina-se por um modo de produção précapitalista, uma técnica pré-industrial e uma ciência pré-moderna que prevalecem, no Brasil como em outros países menos avançados, em boa parte da economia rural.

Essas economias de base rural, em grande medida vivendo da auto-subsistência, estão, é certo, permanentemente em contato com a sociedade moderna envolvente, como decorrência da própria expansão de suas forças produtivas.

Esse contato, no entanto, quase nunca é suficiente para que as sociedades rurais transponham o umbral que as conduz ao desenvolvimento permanente, exponencial, auto-sustentado.

De outra parte, parece hoje fora de dúvida que o Brasil obteve, nas últimas três décadas, mais êxito no encaminhamento das soluções para o crescimento do que para a melhor repartição de seus resultados, condição necessária à extensão, ao maior número, do bem-estar coletivo. Com o processo de repolitização do país, é natu- 
ral que se acentuem o debate e a discussão sobre a questão da distribuição e sobre as funções e as responsabilidades do Estado na condução do processo de repartição social dos frutos do crescimento.

No entanto, o problema da distribuição social da riqueza, - seja pessoal, seja regional, - é mais complexo entre nós, na medida em que se opera em dois planos distintos, ainda que inter-relacionados.

O primeiro plano é o da economia moderna de mercado, onde as desigualdades podem ser atribuídas às disfunções distributivas do capitalismo, cabendo ao Estado a função de corrigi-las.

O segundo plano é o das economias de base tradicional, distanciadas tecnicamente da economia moderna envolvente, a qual é incapaz de modificá-las significativamente pela simples expansão de suas forças produtivas, cabendo portanto ao Estado, como agente de desenvolvimento, buscar transformá-las, mediante ampla e abrangente intervenção promotora de processo irreversível de modernização.

Ainda sobre a questão da distribuição, convém não esquecer, que, do somatório das forças produtivas nacionais, não brota hoje nenhuma superabundância, na medida em que o produto médio per capita do país apenas atinge 2 mil dólares anualmente.

Essa média afasta, de plano, qualquer solução distributivista que se limite a tirar mais, de quem tem mais para dar mais a quem tem menos, sem, concomitantemente, procurar, pela melhoria do desempenho do sistema produtivo, elevar sua eficiência econômica.

No plano político, finalmente, parece pouco provável que as conquistas libertárias sejam compartilhadas igualmente em sociedade que apresenta, no econômico e no social, tão grandes disparidades, o que faz com que elas sejam entendidas, concretamente, mais como pré-condições formais à prática da democracia, necessárias mas não suficientes para engendrar processo de repolitização que se afirme como amplamente participativo.

\section{Urbanização e habitação no Brasil}

Essa digressão algo acadêmica e, sobre aspectos tão gerais do processo de desenvolvimento nas sociedades menos avançadas de hoje e, talvez ajude a compreensão de certas peculiaridades delas, mais próximas do tema central deste estudo.

Primeiro, não se deve entender como urbanização o processo, no dizer de Gilberto Freyre, de "inchação de nossas grandes e médias cidades". Esse crescimento, antes demográfico do que econômico, resulta mais de mera transferência de pobreza do meio rural para o urbano do que propriamente de expansão das forças produtivas urbanas demandando mão-de-obra. Não há dúvida de que as migrações do campo para a cidade, das regiões mais pobres para as mais ricas, das pequenas para as médias e grandes cidades têm, dentro de certos limites, sua funcionalidade e sua relevância econômica - ao assegurar, por exemplo, trabalho abundante e de baixo custo para viabilizar o desenvolvimento das indústrias de transfor- 
mação, da construção civil, dos vários serviços urbanos menos qualificados. Mas essa necessidade de ampliação acelerada do mercado de trabalho urbano não explica migrações na escala das que ocorreram entre nós, nas últimas três décadas (1950-1980), elevando o 'grau de urbanização' do país de 36\% para $68 \%$.

Segundo, é preciso reconhecer os avanços ocorridos no Brasil nos últimos anos, inclusive no campo habitacional, como conseqüência do crescimento, em benefício do bem-estar médio da população. Por exemplo: entre 1950 e 1980, o percentual de domicílios urbanos com abastecimento d'água (com canalização interna) elevou-se de 39\% para 76\% ; o dos domicílios que possuíam instalação sanitária, de $71 \%$ para $91 \%$; o dos com instalação elétrica, de $60 \%$ para $88 \%$. Outro exemplo: em 1960 , apenas 35\% dos domicílios (urbanos e rurais) possuíam rádio; $12 \%$, geladeiras; $5 \%$, televisão; em 1980, esses percentuais eram $76 \%, 49 \%$ e $54 \%$, respectivamente. Mais um exemplo: no periodo entre 1970 e 1980, o percentual de domicílios urbanos com abastecimento d'água (canalização interna) elevou-se de $54 \%$ para $76 \%$; o dos com instalação sanitária, de $86 \%$ para $91 \%$ o dos com iluminação elétrica, de $76 \%$ para $88 \%$; o dos que possuíam rádio, de $72 \%$ para $79 \%$; geladeira, de $42 \%$ para $66 \%$; televisão, de $40 \%$ para $73 \%$; automóvel, de $14 \%$ para $28 \%$.

Terceiro, é importante distingüir, na noção de demanda por habitações referida de início, o que é demanda efetiva, dadas as condições viáveis de oferta, do que é simplesmente necessidade social ou demanda potencial. Na verdade, creio estar implícito no que foi dito antes que a solução de longo prazo para o problema habitacional não está apenas em atuar sobre as condições de oferta sem que se procure, concomitantemente, através da política de desenvolvimento, alterar as condições determinantes da demanda.

Quarto, não se pode perseguir objetivo eminentemente social, como o da melhoria das condiç̃es habitacionais, de forma isolada e estanque, sem considerar amplo conjunto de variáveis - ligadas ao emprego, à formação da renda, à propriedade e ao uso do solo etc - que com ele mantém complexas e múltiplas relações de dependência mútua.

Quinto, convém não subestimar a capacidade de organização comunitária e de conscientização política das comunidades urbanas de baixa renda, sobretudo nas grandes cidades, como fenômeno importante - e positivo - do processo de repolitização por que atravessa o país. Fenômeno capaz de facilitar sua mobilização com o objetivo de solucionar, criativamente, as dificuldades que enfrentam para alcançar melhores níveis de bem-estar social.

\section{A questão da habitação no meio urbano}

Creio útil concentrar a atenção, doravante, por sua óbvia relevância, no problema habitacional urbano do Brasil.

Já se estimou, grosso modo, em 24 milhões, a demanda habitacional urbana potencial dos próximos vinte anos (1980-2000).

Análise dos resultados do Censo demográfico de 1980 - ainda 
não disponíveis, com o grau de detalhe necessário - deverá permitir sua mais correta mensuração. Com base, no entanto, nos dados disponíveis para 1976, sobre distribuição da renda familiar urbana, pode-se estimar a demanda habitacional potencial, por grupo de renda, até o ano 2.000 (ver quadro 1).

Para os grupos de rendimento de até três salários mínimos, essa demanda está estimada em 12,7 milhões de habitações (53\%); para os grupos de três a cinco salários mínimos, em 4,5 milhões (19\%); para os grupos de cinco a dez salários mínimos, em 4,3 miIhões (18\%) e para os grupos acima de dez salários mínimos, em 2,5 milhões $(10 \%)$.

Se nessa perspectiva de vinte anos, a dimensão do problema habitacional assusta, pode-se estimar, com base em projeção do crescimento da população urbana, feita a partir dos dados preliminares do censo demográfico de 1980, a demanda dela decorrente esperada no período de 1981-1985. Para crescimento demográfico urbano, no período, estimado em 17,8 milhões (crescimento médio geométrico anual de 4,1\%), obtém-se demanda potencial de $3,6 \mathrm{mi}$ Ihões de habitações (à razão, ainda mantida, de cinco pessoas por habitação), assim distribuída (ver quadro 2 ):

1. para os grupos de rendimento de até três salários mínimos, 1,6 milhão; 2. para os grupos de três a cinco salários mínimos, 0,7 milhão; 3. para os grupos de cinco a dez salários mínimos, 0,8 miIhão; 4. para os grupos acima de dez salários mínimos, 0,5 milhão.

Essa projeção de demanda compara-se adequadamente com a programação proposta pelo B.N.H. para 1981-1985, que prevê o financiamento de 3,8 milhões de habitações, sendo 3,2 milhões na área de interesse social - até dez salários mínimos e 0,6 milhão para os grupos de rendimento mensal superior a dez salários mínimos (Quadro 2).

A demanda por habitações acima projetada para 1981-1985 não considera a decorrente da redução de déficit habitacional existente em 1980. Para sua diminuição, a oferta de financiamentos habitacionais deveria ser substancialmente ampliada, o que é pouco viável, pelo menos a curto prazo, consideradas as restrições de recursos atualmente enfrentadas pelo Sistema Financeiro da Habitação - S.F.H. De qualquer modo, esta programação da oferta representa grande esforço, uma vez que deverá elevar o número de financiamentos concedidos da média de 240 mil anuais em 1977-1979 para o nivel de 760 mil por ano de 1981-1985. Na perspectiva de longo prazo, pode-se visualizar: período, anterior a 1980, em que o número de financiamentos habitacionais concedidos foi inferior à demanda potencial gerada pela expansão demográfica, ampliando-se, portanto, o déficit habitacional urbano; período, entre 1980 e 1985, em que a oferta de financiamentos se iguala à demanda por habitações decorrente do crescimento da população urbana, tendendo a superá-la, nos últimos anos e período, posterior a 1985, em que seria possível partir-se para gradativa redução do déficit habitacional, mantido, em 1985, nos mesmos níveis ou um pouco abaixo dos de 1980. 
No entanto, uma análise, mais pormenorizada, das condições objetivas da oferta e da demanda por habitações urbanas, no período 1981-1985, se, de uma parte, revela ser necessário muito esforço para que a demanda potencial por habitações se transforme em demanda efetiva, sobretudo no caso das populações de baixa renda, por outro lado sugere que modificações do lado da oferta de habitações, nos aspectos financeiros como nos reais, tendentes a reduzir os custos da habitação, podem alterar importantemente os dados do problema, permitindo, no curto e médio prazos, melhoria significativa nas condições habitacionais das populações urbanas de baixa renda.

É claro que o modo mais eficaz pelo qual a demanda potencial por habitações de baixa renda pode transformar-se em demanda efetiva é a elevação da renda real das populações mais pobres, propiciando-Ihes condições de arcar com os custos dos financiamentos habitacionais. Não se pode, no entanto, esperar que essa redução da probreza, absoluta e relativa, ocorra no curto prazo, ainda que deva constituir-se objetivo permanente da política de desenvolvimento.

Nesse contexto, política habitacional mantida para subsidiar os custos, reais ou financeiros da habitação, é objetivo consistente com a ênfase dinamicamente distributivista conferida ao desenvolvimento, na sua dimensão social. É, além do mais, meio pelo qual se pode elevar, indiretamente, a renda real das populações mais pobres.

O conjunto de instrumentos, fiscais e financeiros, existentes, voltado para esse objetivo já é amplo, mas seus efeitos têm sido absorvidos pelos altos níveis da inflação. Ademais, o fato de que as correções salariais são feitas hoje semestralmente, enquanto que a atualização das prestações devidas pelos mutuários do S.F.H. é feito anualmente, provoca alterações abruptas na renda disponivel que estariam a aconselhar a adoção de calendário semestral também para a correção monetária das obrigações para com o S.F.H. É evidente que, se a atualização semestral dos salários - uma receita - representa ganho para o assalariado, o mesmo procedimento, adotado para as prestações do S.F.H. - uma despesa - , representa perda de renda real, ainda que possa simplificar a distribuição, no tempo, dos orçamentos familiares. No caso, a adoção da correção semestral das prestações do S.F.H. poderia ser opcional para o mutuário, que decidiria sobre o trade-off entre a desvantagem de uma redução de sua renda real anual e a vantagem da simplificação do cálculo econômico familiar. Ou se poderia conceber mecanismo de correção semestral que compensasse, através da capitalização das prestações, as antecipações de receitas obtidas, com a semestralidade, pelo S.F.H.

De toda maneira, a não ser que decisão política assegure ao S.F.H. recursos públicos para ampliar os subsídios aos programas habitacionais para as populações de baixa renda, os efeitos dos atuais incentivos fiscais e financeiros - particularmente os decorrentes da prática de juros diferenciados - somente se farão sentir com grande redução dos níveis atuais da inflação. Ainda que se de- 
va reconhecer que dilatações de prazo ou modificacões nas condições de amortização dos financiamentos habitacionais possam atenuar, no presente, distribuindo para o futuro, comprometimentos da renda familiar que se afigurem demasiado elevados.

O esforço visando à redução do custo privado da oferta de habitações para as populações de baixa renda encontra, de outra parte, sério obstáculo no elevado preço dos terrenos urbanos, sobretudo nos grandes e médios aglomerados urbanos.

Com efeito, cerca de 380 mil hectares deverão ser ocupados, nos próximos vinte anos, com a construção de 15 milhões de habitações, necessárias para abrigar a expansão esperada da população urbana até o ano 2000. Essa área corresponde a mais de seis vezes a área urbana efetivamente ocupada da região metropolitana do Rio de Janeiro.

Nas grandes cidades, o preço dos terrenos urbanos, mesmo em áreas periféricas, tem-se elevado entre 5 e 10\% ao ano, em termos reais, na última década. Esse crescimento, se se deve, de um lado, à rápida expansão da população urbana - das mais elevadas do mundo - deve-se, também, a investimentos imobiliários realizados como forma eficaz de defesa da poupança privada contra os efeitos do processo inflacionário - ainda que, do ponto de vista econômico, sejam esses investimentos improdutivos e de natureza meramente especulativa. Acarretam, ademaiș, essas aplicações imobiliárias a ociosidade de grandes espaços urbanos edificáveis, que atinge, por exemplo, $45 \%$ das áreas urbanas no Município de São Pau10.

Mais que isso, a expansão das áreas urbanizadas e a valorização do solo urbano caminham juntas e são casos típicos de socialização de custos e privatização de benefícios, dificultando, pelo alto preço, a aquisição de terrenos para programas de habitação de interesse social.

A supervalorização dos terrenos urbanos, determinando, muitas vezes, a localização de conjuntos habitacionais em áreas cada vez mais distantes dos núcleos centrais, conduz, ademais, a crescimento desordenado e descontínuo das cidades, com maiores e mais custosas exigências no que respeita à infra-estrutura e aos demais equipamentos urbanos. Há mesmo casos de cidades em que, se os investimentos em infra-estrutura caminham numa direção - e com ela, a valorização imobiliária - , a construção de habitações populares segue direção oposta ou se comporta aleatoriamente, numa expansão desmedida e caótica das periferias urbanas.

Num outro sentido, o crescimento urbano assume o caráter de estranho e cíclico processo de criação destrutiva. Trata-se da substituição, nos núcleos centrais das grandes cidades, de velhas por novas edificações, sempre elevando a densidade da ocupação urbana e exigindo, como contrapartida, maiores investimentos públicos em infra-estrutura. Em certos momentos de sua evolução urbana, esse processo de criação destrutiva - a um tempo determinado pela valorização imobiliária e dela determinante - confere a certos núcleos 
2. Programa de Financiamento de Lotes Urbanizados, criado através da Resolução 018 de 26 de junho de 1975 pelo Conselho Administrativo do Banco Nacional da Habitação - B.N.H., no âmbito do Plano Nacional de Habitação Popular - PLANHAP, como objetivo de urbanização de áreas livres, loteadas ou não, ou de áreas ocupadas por aglomerados de subabitações.

3. Decreto n: 84.156 de 5 de novembro de 1979. urbanos centrais o inquietante aspecto de cidades bombardeadas, em processo de reconstrução.

Socialmente, a excessiva valorização fundiária nas grandes e médias cidades tende a deslocar as populações de menores rendas para áreas cada vez mais periféricas, engendrando indesejável processo de segregação urbana.

Seria útil indagar - ainda que superficialmente - sobre as respostas político-institucionais para reduzir o impacto da valorização fundiária urbana sobre o custo privado da oferta de habitações para as populações de baixa renda.

No que respeita aos loteamentos urbanos, a Lei n. 6.766, de 19 de dezembro de 1979, ao dispor sobre o parcelamento do solo urbano, pode ser fator de deflagração de processo de controle da forma atualmente mais importante da expansão urbana das cidades brasileiras, sobretudo no caso das áreas destinadas a habitações populares, possibilitando maior adequação entre o custo dos lotes populares e capacidade aquisitiva das familias de menores rendas. Acoplado ao PROFILURB ${ }^{2}$, esse processo de controle a nível municipal, pode resultar em resposta importante para viabilizar programas alternativos de habitação popular.

Para preencher os vazios urbanos, a iniciativa do B.N.H. de criar uma Diretoria de Terras ${ }^{3}$ com o objetivo de executar política de aquisição, para fins habitacionais, de áreas onde a implantação ou complementação da infra-estrutura e dos outros equipamentos urbanos envolvem menores custos, pode também ser caminho para a ocupação desses espaços ou a criação de outros, se esse esforço for acompanhado de medidas fiscais e institucionais como o imposto progressivo sobre terrenos urbanos não edificados e a sua utilização compulsória. Importa ressaltar, neste contexto, a importância da compra antecipada de terrenos que possam atender às necessidades de médio prazo dos programas habitacionais.

No fundo da questão, no entanto, está o fato de que somente será viável o atendimento da demanda por habitações das populações de baixa renda, se não lhes for imputado o custo da valorização fundiária urbana. Destaque-se, para evidenciar a relevância do ônus atual das terras urbanas, que, em muitas áreas periféricas urbanas, o custo de lotes para populações de baixa renda pode equivaler entre 30 e $50 \%$ do custo de produção total de habitações.

Ainda com relação às modificações nas condições de oferta de habitações, é importante considerar o efeito, sobre os custos reais da construção, da ampliação pretendida para os programas habitacionais, nos próximos anos.

Como é sabido, o B.N.H. elevou o número de financiamentos habitacionais concedidos de 226 mil em 1977 para 337 mil em 1978 , 383 mil em 1979 e 548 mil em 1980. Estima-se que, atualmente, encontram-se em construção em todo o país, cerca de 650 mil habitações, e se pretende elevar o número de financiamentos habitacionais concedidos para 760 mil ao ano, na média do período 1981 1985. Essa expansão, ao pressionar o mercado de materiais de cons- 
4. Programa de Erradicação de Subabitação, criado em decorrência do despacho do Presidente da República de 25 de junho de 1979, exarada na Exposição de Motivos interministerial n: 66 da mesma data.

5. É o principal projeto do PRO MORAR. Vinculado à Diretoria de Programas Habitacionais, executado diretamente pela Carteira de Erradicação de Subabitação e Emergências Sociais, tem a sua área de atuação na Baia da Gua nabara, na região que vai da ponta do Caju até a foz do rio lguaçu, no Municipio de Duque de $\mathrm{Ca}$ xias, onde se concentram seis favelas reunidas na 'Favela da $\mathrm{Ma}$ ré', com um total de 250 mil habitantes. trução, poderá acarretar elevação de seus preços relativos, onerando, ainda mais, os custos da construção. É importante, assim, atentar para os aspectos reais da indústria de materiais de construção para que eventuais insuficiências de oferta não venham a constituirse, no futuro, fator limitativo de programação que, em outras circunstâncias, seria econômica e financeiramente factível.

\section{Programas alternativos de melhoria das condições de habitação nas cidades}

Quero referir-me, para finalizar, à questão da ocupação espontânea de áreas urbanas por assentamentos humanos de baixa renda, para destacar a importância de sua regularização como fator importante para a redução, a médio prazo, do déficit habitacional nas grandes e médias cidades brasileiras.

A mudança da postura governamental com relação a esses assentamentos subnormais, hoje contrária a sua remoção e favorável a sua manutenção e recuperação, é avanço importante do desenvolvimento social urbano entre nós.

Essa nova abordagem, simbolizada pelo $\mathrm{PROMORAR}^{4} \mathrm{e}$, particularmente, pelo Projeto Rio, ${ }^{5}$, aponta para a regularização fundiária desse assentamento e para a melhoria de suas condições habitacionais e de urbanização.

A questão da regularização jurídica das áreas urbanas ocupadas por favelas não é, a meu ver, questão que se possa resolver simplesmente mediante legislação específica, que se fundamente no princípio constitucional que confere função social à propriedade. Ainda que instrumentos legais como o do usucapião urbano ou o direito de superfície possam ser úteis, a questão pode resolver-se, de forma não conflitiva, mediante negociação. No caso dos terrenos públicos, ação executiva, respaldada em clara decisão de política governamental, envolvendo a União, os Estados e os Municípios, pode sobrepujar os complexos obstáculos burocráticos comumente encontrados. Não creio que se deva doá-los, pelo simples fato de que são bens públicos, mas aliená-los, quando necessário, a preços e condições de financiamento compatíveis com a capacidade aquisitiva das populações beneficiadas. No caso das terras de propriedade privada, há que atentar-se para o seu baixo potencial de uso alternativo - mormente no caso de grandes e antigas invasões - para, pela negociação, tentar viabilizar sua alienação em condições que permitam sua aquisição pelas famílias de baixa renda. Os procedimentos expropriatórios somente devem ser utilizados in extremis, e são lentos, caros, penosos. De outra parte, as propostas de alteração da legislação sobre desapropriação em áreas urbanas devem ser examinadas com muito cuidado. Cuidado para que não se agrave, em lugar de atenuar-se o problema que visam a resolver e para que não se ampliem as tensões sociais decorrentes dessas ocupações irregulares.

Na verdade, o importante, nesses casos, é assegurar o domínio ou a posse, por essas populações, das áreas que habitam, condição de segurança que permitirá que caminhem, com confiança, pa- 
ra a melhoria de suas condições de habitação e para que se possa executar modelos de urbanização objeto de regulamentação especial e que atentem para as peculiaridades desses assentamentos subnormais.

\section{A Necessidade e a urgência de soluções}

De tudo o que se disse acima, sobressai a dimensão do problema que a sociedade brasileira deverá enfrentar, nos próximos anos, para equacionar a questão social da habitação.

Trata-se de problema cuja grandeza não deve assustar, mas que não pode, de outra parte, ser subestimado, sob pena de se acentuarem, perigosamente, os grandes contrastes sociais que hoje se vêem nas grandes cidades brasileiras. Contrastes que nos dizem claramente que os benefícios do desenvolvimento ainda são privilégio de poucos, mas que não podem significar que assim deva continuar sendo, por muito tempo, conduzindo a sociedade a tensões tanto maiores quanto menores forem a segurança e a confiança na extensão, à maioria, do bem-estar social.

\section{Quadro 1}

Estimativa da demanda habitacional urbana, por grupos de rendimento mensal domiciliar, 1980-2000

\begin{tabular}{l|c|c|c}
\hline \multirow{2}{*}{$\begin{array}{l}\text { Grupo de } \\
\text { rendimento } \\
\text { (Salário minimo) }\end{array}$} & $\begin{array}{c}\text { Demanda habitacional (milhões de unidades) } \\
\text { cecorrente do } \\
\text { demográfico }\end{array}$ & $\begin{array}{c}\text { Para cobrir o } \\
\text { déficit estimado } \\
\text { para 1980 }\end{array}$ & Total \\
\hline Até 3 & 6,8 & 5,9 & 12,7 \\
Mais de 3 a 5 & 2,8 & 1,7 & 4,5 \\
Mais de 5 a 10 & 3,3 & 0,0 & 4,3 \\
Mais de 10 & 2,1 & 9,5 & 2,5 \\
\hline TOTAL & 15,0 & 9,0 & 24,0 \\
\hline
\end{tabular}

\section{Quadro 2}

Estimativa da demanda habitacional urbana (decorrente do crescimento demográfico) e da oferta programada, 1981-1985 (em milhões)

\begin{tabular}{l|c|c}
\hline $\begin{array}{l}\text { Grupo de rendimento } \\
\text { (Salário minimo) }\end{array}$ & $\begin{array}{c}\text { Demanda } \\
\text { habitacional }\end{array}$ & $\begin{array}{c}\text { Oferta programada } \\
\text { (B.N.H.) }\end{array}$ \\
\hline Até 5 & 2,3 & 2,4 \\
De 5 a 10 & 0,8 & 0,8 \\
Mais de 10 & 0,5 & 0,6 \\
\hline TOTAL & 3,6 & 3,8 \\
\hline
\end{tabular}




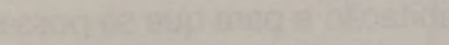

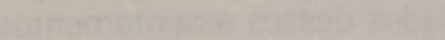

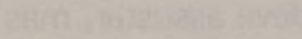

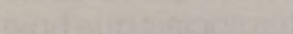

C-

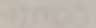

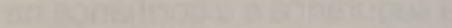

(3)

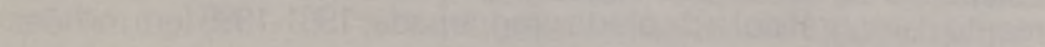

